\title{
Origin of mouse embryonal carcinoma cells and the possibility of their direct isolation into tissue culture
}

\author{
Martin Evans
}

Department of Genetics, University of Cambridge, Downing Street, Cambridge CB2 3EH, U.K.

A few years ago teratocarcinomas and in particular the use of cultures of their stem cells-so called embryonal carcinoma cells - were not widely appreciated and it was a useful exercise to present the essential features of them as a system for the study of cell determination and differentiation. Now, however, there is even some danger that the inherent diversity of the presently available lines may lead to enthusiatic but unwarranted generalizations about the properties and behaviour of embryonic cells. In this paper I shall, therefore, only briefly outline some of the types of investigation which are facilitated by the use of embryonal carcinoma cells in culture and I shall discuss the relationship of such cells to cell lineages in the normal embryo. This paper does not attempt to provide a review of the subject which has been fairly comprehensively covered already (Stevens, 1967; Pierce, 1967; Damjanov \& Solter, 1974; Martin, 1975, 1978; Graham, 1977; Hogan, 1977). Although many papers have been published since the dates of these reviews there has been little substantial or conceptual change in this field.

The essential feature of embryonal carcinoma cells is their pluripotency. Their phenotype is very similar to that of primordial germ cells and to pluripotential cells of the early embryo both in appearance and in cell surface antigen constitution, but unlike these cells they may be isolated and maintained in tissue culture as cell lines. Some of these lines differentiate in vitro in a manner very similar to that of isolated embryonic inner cell masses (reviewed by Martin, 1977). Their apparent homology with early embryo cells is greatly strengthened by the ability of some cell culture lines to colonize mouse embryos and participate in the formation of chimaeric mice, contributing to many normal tissues (Papaioannou, McBurney, Gardner \& Evans, 1975; Papaioannou, Gardner, McBurney, Babinet \& Evans, 1978; Dewey, Martin, Martin \& Mintz, 1978).

There is a considerable variation amongst various embryonal carcinoma cell lines. They may have different growth characteristics in culture and display to various degrees the ability to differentiate into a wide variety of tissues. Some lines differentiate well in vitro, going through an embryoid body configuration and subsequently spreading on the culture plate to produce very many types of cell; others differentiate equally well but do not go through an overt embryoid body formation; others differentiate only in a tumour in vivo; whilst yet others differentiate very poorly in any circumstances. There is, however, evidence that even these latter 'nullipotential' lines may be induced to differentiate into at least one other cell type by treatment with retinoic acid (Jetten, Jetten \& Sherman, 1979) or other reagents (Speers, Birdwell \& Dixon, 1979).

Most embryonal carcinoma cell lines in culture are aneuploid (although in contrast to other established mouse tumour cell lines the chromosome number is approximately normal). Small chromosomal re-arrangements are found and many lines are XO (reviewed by Graham, 1977). More recently new lines of cells from teratocarcinomas have been made which are apparently euploid. Unfortunately, none has, as yet, been reported to be able to differentiate well in vitro or, more importantly, to form a chimaeric mouse with germ cell contributions.

Embryonal carcinoma cells are not strictly normal cells and display a range of differentiative capacity and behaviour, but they have several advantageous features from an 
experimental point of view. These are principally advantages (compared with the normal embryo) of accessibility, scale, and ease of manipulation and modification. Tissue culture allows the use of large homogeneous populations of cells which therefore lend themselves to biochemical or immunological studies. The availability of such cells also allows the use of all the manipulative and selective techniques which have been developed for tissue culture cells, e.g. cell hybridization experiments, selection of mutants and treatment with exogenous effectors. One particularly fascinating aspect is that they may be used as vehicles into which recombinant DNA molecules may be inserted. This will allow an analysis of expression of such molecules in a system in which cell determination and differentiation will take place (Pellicer et al., 1980).

For many experimental purposes it would be advantageous if perfectly normal embryonic cells could be cultured and manipulated in the same way as embryonal carcinoma cells. On the other hand, cell lines with specific abnormal properties can be very useful. For example, F9 cells have been experimentally important despite being a line which has lost practically all its differentiative capacity (Jacob, 1977).

The present understanding of the biology of teratocarcinoma in mice owes its origin almost exclusively to Stevens and his collaborators. He demonstrated that the spontaneous origin of teratocarcinoma in the testes of strain 129 mice was from germ cells during fetal development and that experimental transplantation of 11-12-day post coitum fetal germinal ridges to an adult host testis allowed teratocarcinoma formation at a high frequency. The male germinal ridges formed fetal testes in which nests of germ cells proliferated to become the teratocarcinoma stem cell (reviewed by Stevens, 1967). Teratocarcinomas may also be induced to form experimentally by the implantation of young embryos into ectopic sites (Stevens, 1968, 1970; Solter, Skreb \& Damjanov, 1970). Spontaneous ovarian teratomas are found in strain LT mice and arise from parthenogenetically activated oocytes which develop ectopically into early embryos and thence teratomas (Stevens \& Varnum, 1974).

To begin to understand any processes of control of normal development it is useful to observe the effect of experimental perturbations from the normal. One of the features of development of embryos of placental mammals is the closely controlled maternal uterine environment. Ectopic implantation, although in some cases leading to surprisingly normal embryogenesis, often leads to an abortive development which results in a miscellany of disorganized tissues. Ectopic implantation of a mouse embryo may result in such a tumour which is benign, an embryoma or teratoma, or may result in a larger tumour which grows progressively (and may sometimes be passaged in histocompatible hosts). This is a teratocarcinoma and owes its continuing growth characteristic to a component of proliferating pluripotential cells which not only provide the source of the differentiated tissues in the tumours but also maintain themselves as a stem cell line. In many cases, either in the primary site or in subsequent experimental passage, the stem cell population becomes lost and the tumour reverts to being an embryoma, or teratoma as it is more usually termed. It has been shown that although any stage of embryo between 2 -cell and $7 \frac{1}{2}$ days of development may give rise to a teratocarcinoma, embryos later than this stage give rise only to teratomas (Stevens, 1968, 1970; Solter et al., 1970; Damjanov, Solter \& Skreb, 1971).

One approach to the relationship between embryonal carcinoma cells and normal embryonic cells is to consider the cells of origin of the teratocarcinoma. Cell determination is thought of as the irreversible restriction of potential cell fate in cells of a particular lineage. If this concept truly reflects cell behaviour one might expect that pluripotential cells exist only as a germ cell line and in the early embryo before determination to the somatic lines has occurred. The stem cells of teratocarcinomas, as they are themselves pluripotential, therefore arise either from germ cells or from pluripotential embryonic cells. It is clear that the former explanation reasonably accounts for testicular teratocarcinomas and those formed by ectopic transplantation of germinal ridges. Either might explain their origin from embryos but the observations of Mintz, Cronmiller \& Custer (1978) suggest that germ cells may not be involved. They found that $\mathrm{W} / \mathrm{W}$ homozygous 
embryos could give rise to teratocarcinomas although $\mathrm{W} / \mathrm{W}$ mice are severely deficient in germ cells. This deficiency is, however, only observable at a later stage of embryogenesis as germ cells are not distinguishable until about 1 day after the last stage at which the transplanted embryo is able to produce a teratocarcinoma (Odzenski, 1967).

Solter \& Damjanov (1973) demonstrated that it is only the embryonic portion of the egg cylinder stage which is capable of giving rise to a teratocarcinoma and Diwan \& Stevens (1976) have shown that it is the embryonic ectoderm which is the effective component. In complete contrast to these experiments, Sobis \& Vanderputte (1975) have shown that ectopic yolk sac of rat embryos can form teratomas: whether true teratocarcinomas can arise in this manner is less clear. These results seem surprising as none of the cells in the yolk sac was thought of as pluripotential. The possibility of primordial germ cells being included in the yolk is rendered unlikely by experiments in which the embryos were depleted of primordial germ cells by busulphan treatment (Sobis \& Vanderputte, 1976).

In the present consideration of embryo-maternal relationships it is worth noting that the frequency of teratocarcinoma versus teratoma formation from an embryo is influenced by the inbred strain of mouse used (reviewed by Solter, Damjanov \& Koprowski, 1975). Perhaps surprisingly, it was found that this was not an effect of genotype upon the embryonic cells themselves but upon their environment in the host animal. Embryos of the mouse strain C57BL, for example, when transplanted beneath the kidney capsule of a mouse of the same strain gave rise predominantly to teratomas, but the same experiment with $\mathrm{C} 3 \mathrm{H}$ mice gave a very high frequency of teratocarcinomas. C57BL embryos transplanted to the histocompatible C57BL/C3H F 1 hybrid host, however, gave rise to teratocarcinomas.

Embryonal carcinoma cells may then be derived from two different types of cell, either from a pluripotential early embryonic cell or from a primordial germ cell. A close comparison of the cell phenotype of embryonal carcinoma cells with those of primordial germ cells and various pluripotential early embryonic cells may help to pinpoint their homology. A considerable number of specific antigens on embryonal carcinoma cell surfaces have been described (see Jacob, 1977). These antigens are typically expressed on the surface of primordial germ cells and some early embryonic cells. "F9 antigen", for instance, has been shown to be present up to the 7 th day of development as well as on the surface of primordial germ cells and spermatozoa. Such a typical spectrum of cell specificity confirms the apparent homologies but cannot subdivide them.

We have recently been able to make use of the specificity of a monoclonal antibody preparation, $\mathrm{M} 1 / 22.25$, which recognizes a determinant of the Forssman antigen, to explore these homologies further (Stern et al., 1978). This determinant is not present on spermatozoa or any other cell in the germ cell lineage of the adult mouse, but only on Sertoli cells in the testis. It is expressed on embryonal carcinoma cells, primordial germ cells, late morula cells and cells of the inner cell mass but not on embryonic ectoderm and after Day $6 \frac{1}{2}$ post coitum. At this time it is present on the non-pluripotential endodermal cell lineages (Evans, Lovell-Badge, Stern \& Stinnakre, 1979; Stinnakre, Evans, Willison \& Stern, 1981). If expression of such a cell surface antigen is a significant indicator of cell differentiation, it suggests that, if ectodermal cells are the embryonic homologue of embryonal carcinoma cells, this is at a phenotypic stage before that of $6 \frac{1}{2}$ days of development. The cell surface (or other phenotype) does not, however, necessarily reflect the cell's determinative state so these observations do not rule out the possibility of a de-differentiative process such that $>6$-day ectoderm becomes transformed into the precursor of embryonal carcinoma cells in vivo.

The other method by which we have sought to discriminate cell phenotype has been to use two-dimensional gel electrophoresis to provide a spectrum of total protein synthesis. We have compared embryonal carcinoma cells with isolated inner cell masses from $3 \frac{1}{2}$-day-old blastocysts and concluded, as have other authors (Dewey, Filler \& Mintz, 1978; Failly-Crepin \& Martin, 1979), that the two protein synthesis patterns were in no way the same (Lovell-Badge \& Evans, 
1980). We have also compared the pattern with that of $6 \frac{1}{2}$ and $7 \frac{1}{2}$ day separated embryonic ectoderm and embryonic endoderm, with 5-day endoderm + ectoderm, and with isolated primordial germ cells. Out of over 1000 spots resolved on the autofluorographs, only 19 showed consistent variation between all the samples studied. Eighteen of these, including 4 that were present in all the other samples, were conspicuous by their absence from the germ cells. Four spots found in embryonal carcinoma cells were missing from $7 \frac{1}{2}$ day ectoderm and only 2 of these 4 appeared in $6 \frac{1}{2}$ day ectoderm. All four were present in the 5-day embryo. Overall the best match was between embryonal carcinoma cells aggregated into small clumps and labelled during the first $3 \mathrm{~h}$ of their suspension free from a solid substratum and the 5-day embryo (Evans et al., 1979). These observations suggest that neither germ cells nor $>6$-day ectoderm are phenotypically homologous to embryonal carcinoma cells and nor are cells of the inner cell mass of a $3 \frac{1}{2}$ day post coitum blastocyst.

Embryonal carcinoma cells may be cultured from teratocarcinomas and, although the establishment of such cultures from a solid tumour is difficult when they are present only in low numbers, they appear to grow readily on a cell feeder layer as soon as they are isolated. It should, therefore, be straightforward to grow embryonal carcinoma cells directly from explanted germinal ridges or embryos. Such has not, however, been the case.

Primordial germ cells isolated from $11 \frac{1}{2}$ or $12 \frac{1}{2}$ day mouse germinal ridges do not divide in culture, either alone or upon monolayers of fibroblast feeder cells, or feeder layers of their own stromal cells. This was despite considerable attempts to adjust the medium and the surface substratum to optimize conditions (M. G. Stinnakre \& M. J. Evans, unpublished observations). In organ culture the whole or part of the ridge continues to develop normally for some days. Stevens (1975) has shown that the teratocarcinomas can develop directly in vivo from a transplanted fetal germinal ridge. This suggests that the period at which it is straightforward to isolate the germ cells and during which transplantation results in teratocarcinoma formation may not coincide with the period at which the germ cells themselves are able to form embryonal carcinoma cells. Possibly culture from later stages of fetal testis development might be more successful.

The early embryo should provide a more amenable source for the direct isolation of pluripotential cells into tissue culture. Here the appropriate cells must be present between the blastocyst stage and $7 \frac{1}{2}$ days of development or be able to develop from such stages. Explanted blastocysts will develop through this period in more or less standard tissue culture conditions (Hsu \& Baskar, 1974; Sherman, 1975a). Direct culture of a pluripotential cell line from early pre- or post-implantation embryos has not yet, however, been achieved. It is worth considering several possible explanations for this.

In the first place the number of pluripotential cells in the embryo at any one time is very low. The numbers may be sufficient in vivo but insufficient in vitro where greater cell mortality at an

\section{PLATE 1}

Figs 1 and 2. Sheet of cells with an undifferentiated appearance from a $6 \frac{1}{2}$ day mouse embryo stained with fluorescein-conjugated M1/22.25 monoclonal anti-Forssman antibody. The cells have been mounted beneath a coverslip and the endodermal cells, some of which were originally on top of the edge of the sheet, have been squashed at the periphery. Fig. 1, phase contrast; Fig. 2, fluorescence.

Fig. 3. Endodermal cells growing as a monolayer shortly after isolation from a differentiated inner cell mass.

Figs 4 and 5. Endodermal line ICME-2; these cells have the appearance of parietal endoderm. They often detach from the dish singly (Fig. 4) or in clumps forming vesicles (Fig. 5).

Fig. 6. Endodermal line ICME-12; showing cells growing in a very flat epithelium. 
PLATE 1
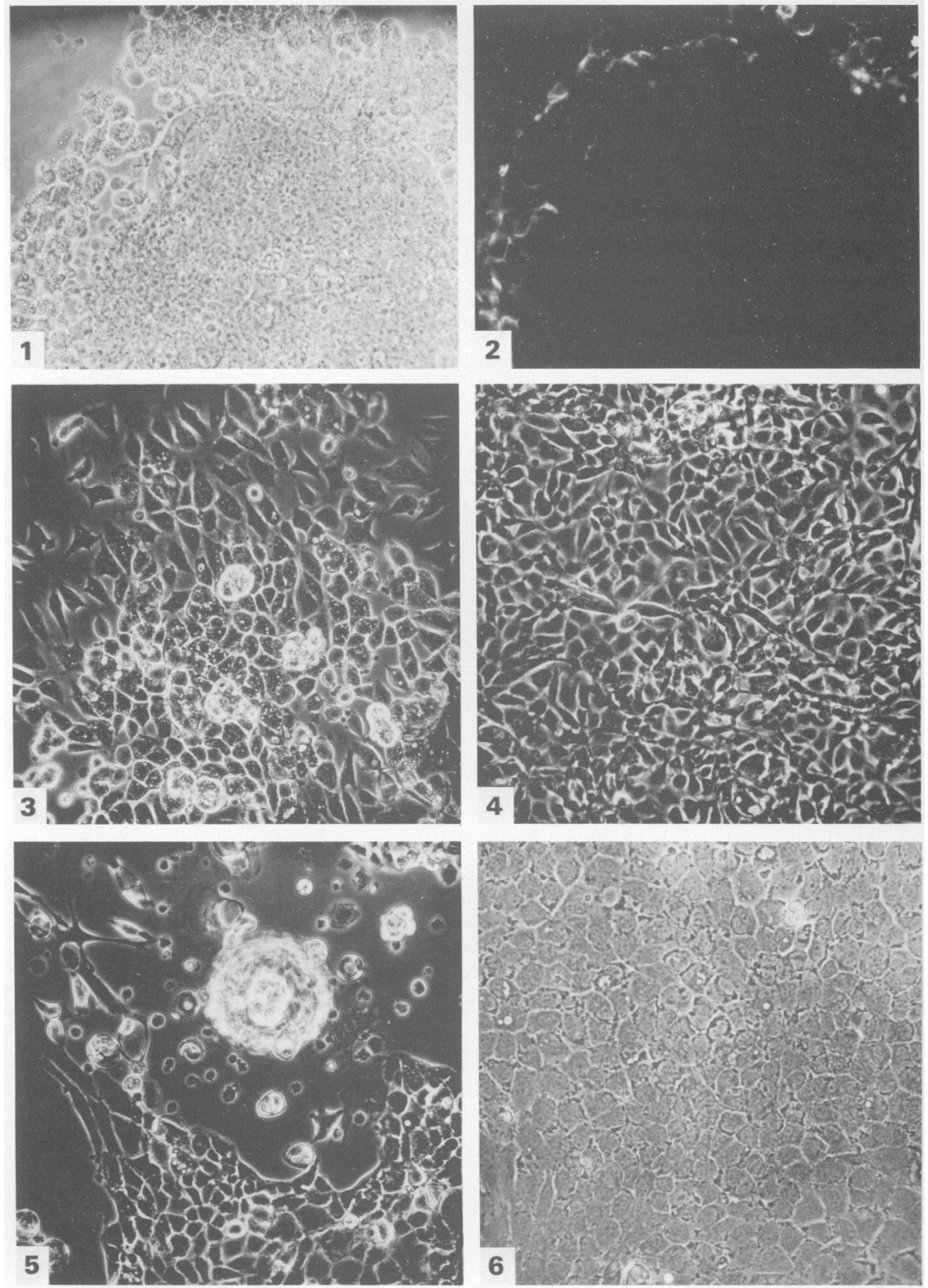

(Facing p. 628) 
earlier stage may be expected. Secondly, the population of pluripotential cells that are able to become embryonal carcinoma cells may exist for only a short time at an exact phase of embryogenesis. The extended time period over which the experimental ectopic implantation of an embryo may give rise to a teratocarcinoma may reflect two processes which can take place in vivo: development of the embryo up to the critical stage, and regression of some of the embryo cells to that stage following the disruption of transplantation, possibly as a result of an attempted regulation of the damaged egg cylinder. In vitro, in monolayer or explant culture, this development or regulation may not be able to occur as the embryo is too disorganized or fragmented. Thirdly, embryonal carcinoma cell lines which differentiate in vitro are difficult to maintain in an undifferentiated state, even with the help of feeder layers. It is very likely that even these lines have already been highly selected for the ability to be maintained in tissue culture and concomitantly for a less ready differentiation. Their genuine embryonic cell counterpart may differentiate and lose its pluripotency and rapid growth characteristics all too readily under culture conditions. In vivo there may be a selective advantage for the overgrowth of embryonal carcinoma cells and the compact tissue environment may help to inhibit their precocious differentiation.

During the past few years we have been attempting to grow cells directly from normal embryos. There are some indications from these studies to support the second two explanations given above for the failure to obtain pluripotential cells.

Explant-cultures of $6 \frac{1}{2}$ and $7 \frac{1}{2}$ day embryos differentiate very well in culture but from small explants sheets of a cell type resembling undifferentiated cells may sometimes be found. They have a less compact appearance than embryonal carcinoma cell colonies. Their difference from embryonal carcinoma cells is also attested by their lack of surface staining with fluoresceinconjugated M1/22.25. The associated endodermal cells, in contrast, do stain brightly (Pl. 1, Figs 1 and 2). Total disaggregation of these embryos or of the cell sheets established in culture and passage on or off cell feeder layers has so far failed to give progressively growing cultures.

The other readily available source of embryonic cells is blastocysts. Attempts at establishing progressive cultures from isolated inner cell masses grown with or without feeder layers have not so far given rise to cultures of pluripotential cells, but lines of an apparently endodermal nature have been isolated (Sherman, 1975b). Inner cell masses were isolated from $3 \frac{1}{2}$ day blastocysts by immunosurgery (Solter \& Knowles, 1975) and allowed to aggregate together on a mitomycin-treated STO fibroblast feeder layer. After 2 days the endodermal cells which had formed around the inner cell masses were removed by dissection after a brief trypsin treatment. They were further disaggregated by trypsin treatment and cultured (Pl. 1, Fig. 3). After a mass culture was established, a series of clones was isolated and these displayed several different morphologies in culture. Two typical lines are shown in Pl. 1, Figs 4, 5 and 6. The relationship between such clones and the different types of endoderm in the normal embryo remains to be fully investigated. Two-dimensional gel electrophoresis patterns, however, demonstrate the typical endodermal polypeptide spots previously described (R. H. Lovell-Badge, unpublished). Endodermal cells can therefore grow. In contrast, no cell lines with an undifferentiated phenotype have been obtained from isolated inner cell masses although Atienza-Samols \& Sherman (1978) have reported their transient occurrence. Solter \& Knowles (1975) reported that some immunosurgically isolated inner cell masses gave rise to cultures containing areas of small cells with large nuclei containing large nucleoli. These would appear to be the sought-after cells of an undifferentiated phenotype but their further growth has not been reported.

In conclusion it still appears possible that pluripotential embryonic cells might be obtainable in culture directly from the embryo. Culture experience to date and considerations of cell phenotype discussed above would suggest that cells of the ectodermal line from embryos between the $3 \frac{1}{2}$ day blastocyst and $6 \frac{1}{2}$ day egg-cylinder stages are the most promising source of pluripotential cells for culture. Cells from this age bracket have not been sufficiently investigated. Conditions of culture which are not conducive to differentiation of the cells will be essential. 


\section{References}

Atienza-Samols, S.B. \& Sherman, M.I. (1978) Outgrowth promoting factor for the inner cell mass of the mouse blastocyst. Devl Biol. 66, 220-231.

Damjanov, I. \& Solter, D. (1974) Experimental teratoma. Current Topics in Pathology 59, 69-130.

Damjanov, I., Solter, D. \& Skreb, N. (1971) Teratocarcinogenesis as related to the age of embryos grafted under the kidney capsule. Wilhelm Roux Arch. EntwMech. Org. 167, 288-290.

Dewey, M.J., Filler, R. \& Mintz, B. (1978) Protein patterns of developmentally totipotent mouse teratocarcinoma cells. Devl Biol. 65, 171-182.

Dewey, M.J., Martin, D.W.M., Martin, G.R. \& Mintz, B. (1978) Mosaic mice with teratocarcinoma-derived mutant cells deficient in hypoxanthine phosphoribosyl transferase. Proc. natn. Acad. Sci. U.S.A. 74, 5564-5568.

Diwan, S.B. \& Stevens, L.C. (1976) Development of teratomas from the ectoderm of mouse egg cylinders. J. natn. Cancer Inst. 57, 937-942.

Evans, M.J., Lovell-Badge, R.H., Stern, P.L. \& Stinnakre, M.G. (1979) In Cell Lineage, Stem Cells and Cell Determination (INSERM Symposium No. 10), pp. 115-129. Ed. N. Le Douarin. Elsevier/NorthHolland Biomedical Press, Amsterdam.

Failly-Crepin, C. \& Martin, G.R. (1979) Protein synthesis and differentiation in a clonal line of teratocarcinoma and in pre-implantation mouse embryo. Cell Differentiation 8, 61-73.

Graham, C.F. (1977) Teratocarcinoma cells and normal mouse embryogenesis. In Concepts in Mammalian Embryogenesis, pp. 315-394. Ed. N. Sherman. MIT press, Cambridge, Massachusetts.

Hogan, B.L.M. (1977) Teratocarcinoma cells as a model for mammalian development. In Biochemistry of Cell Differentiation II, Vol. 15, pp. 333-376. Ed. J. Paul. University Park Press, Baltimore.

Hsu, Y.-C. \& Baskar, J. (1974) Differentiation in vitro of normal mouse embryos and mouse embryonal carcinoma. J. natn. Cancer Inst. 53, 177-185.

Jacob, F. (1977) Mouse teratocarcinomas and embryonic antigens. Immunol. Rev. 33, 3-32.

Jetten, A.M., Jetten, M.E.R. \& Sherman, M.I. (1979) Stimulation of several mouse embryonal carcinogen cell lines by retinoic acid. Expl Cell Res. 124, 381-391.

Lovell-Badge, R.H. \& Evans, M.J. (1980) Changes in protein synthesis during differentiation of embryonal carcinoma cells, and a comparison with embryo cells. J. Embryol. exp. Morph. 59, 187-206.

Martin, G.R. (1975) Teratocarcinomas as a model system for the study of embryogenesis and neoplasia: review. Cell 5, 229-243.

Martin, G.R. (1977) The differentiation of teratocarcinoma stem cells in vitro: parallels to normal embryogenesis. In Cell Interactions in Differentiation, pp. 59-75. Ed. M. KarkinenJaaskelainen, L. Saxen \& L. Weiss. Academic Press, London.

Martin, G.R. (1978) Advantages and limitations of teratocarcinoma stem cells as models of development. In Development in Mammals, Vol. 3, pp. 225-265.
Ed. M. H. Johnson. North-Holland Publishing Co., Amsterdam.

Mintz, B., Cronmiller, C. \& Custer, R.P. (1978) Somatic cell origin of teratocarcinomas. Proc. natn. Acad. Sci. U.S.A. 75, 2834-2838.

Odzenski, W. (1967) Observations on the origins of primordial germ cells in the mouse. Zool. Pol. 17, 367-379.

Papaioannou, V.E., McBurney, M.W., Gardner, R.J. \& Evans, M.J. (1975) Fate of teratocarcinoma cells injected into early mouse embryos. Nature, Lond. 258, $70-73$.

Papaioannou, V.E., Gardner, R., McBurney, M.W., Babinet, C. \& Evans, M.J. (1978) Participation of cultured teratocarcinoma cells in mouse embryo-genesis. J. Embryol. exp. Morphol. 44, 93104.

Pellicer, A., Wagner, E.F., El Koreh, A., Dewey, M.J., Reuser, A.J., Silverstein, S., Axel, R. \& Mintz, B. (1980) Introduction of a viral thymidine kinase gene and the human beta-globin gene into developmentally multipotential mouse teratocarcinoma cells Proc. natn. Acad. Sci. U.S.A. 77, 2098-2102.

Pierce, G.B. (1967) Teratocarcinoma: model for a developmental concept of cancer. Current Top. Dev. Biol. 2, 223-246.

Sherman, M.I. (1975a) The culture of cells derived from mouse blastocysts. Review. Cell 5, 343-349.

Sherman, M.I. (1975b) Long term culture of cells from mouse blastocysts. Differentiation 3, 51-67.

Sobis, H. \& Vandeputte, M. (1975) Sequential morphological study of teratomas from displaced yolk sac. Devl Biol, 45, 276-290.

Sobis, H. \& Vandeputte, M. (1976) Yolk sac derived teratomas are not of germ cell origin. Devl Biol. 51, $320-323$.

Solter, D. \& Damjanov, I. (1973) Explanation of extraembryonic parts of 7-day-old mouse egg cylinders. Experientia 29, 701.

Solter, D. \& Knowles, B. (1975) Immunosurgery of mouse blastocyst. Proc. natn. Acad. Sci. U.S.A. 72, 5099-5102.

Solter, D., Skreb, W. \& Damjanov, I. (1970) Extrauterine growth of mouse egg cylinders results in malignant teratomas. Nature, Lond. 227, 503-504.

Solter, D., Damjanov, I. \& Koprowski, H. (1975) Embryo-derived teratomas: a model system in developmental and tumour biology. In The Early Development of Mammals, pp. 243-264. Eds N. Balls \& A. E. Wild. Cambridge University Press.

Speers, W.C., Birdwell, C.R. \& Dixon, F. J. (1979) Chemically induced bidirectional differentiation of embryonal carcinoma cells in vitro. Am. J. Path. 97, $563-570$.

Stern, P. L., Willison, K., Lennox, E., Galfre, G., Milstein, L., Secker, D., Ziegler, A. \& Springer, T. (1978) Monoclonal antibodies as probes for differentiation and tumour-associated antigens: a Forssman specificity on teratocarcinoma stem cells. Cell 14, $775-783$.

Stevens, L.C. (1967) The biology of teratomas. $A d v$. Morph. 6, 1-31. 
Stevens, L.C. (1968) The development of teratomas from intra-testicular grafts of tubal mouse eggs. J. Embryol. exp. Morph. 20, 329-341.

Stevens, L.C. (1970) The developmental of transplantable teratocarcinomas from intratesticular grafts of pre- and post-implantation mouse embryos. Devl Biol. 21, 364-382.

Stevens, L.C. (1975) Comparative development of normal and parthenogenetic mouse embryos, early testicular and ovarian teratomas, and embroid bodies. In Roche Symposium of Teratomas and Differentiation, pp. 17-32. Eds M. Sherman \& D. Solter. Academic Press, New York.

Stevens, L.C. \& Varnum, D.S. (1974) The development of teratomas from parthenogenetically activated ovarian mouse eggs. Devl Biol. 37, 369-380.

Stinnakre, M.G., Evans, M.J., Willison, K.R. \& Stern, P.L. (1981) Expression of Forssman antigen in the post-implantation mouse embryos. J. Embryol. exp. Morph. 61, 117-131. 